\title{
Impact of percutaneous invasive coronary procedures using a radial approach on endothelial function of radial artery
}

\author{
Karol Sabatowski ${ }^{1}$, Michał Szotek ${ }^{1}$, Krzysztof Węgrzyn $^{1}$, Tomasz Tokarek ${ }^{1}$, Zbigniew Siudak ${ }^{2}$, Dariusz Dudek ${ }^{1,3}$ \\ ${ }^{1} 2^{\text {nd }}$ Department of Cardiology and Cardiovascular Interventions, University Hospital, Krakow, Poland \\ ${ }^{2}$ Faculty of Medicine and Health Sciences, Jan Kochanowski University, Kielce, Poland \\ ${ }^{3} 2^{\text {nd }}$ Department of Cardiology, Institute of Cardiology, Jagiellonian University Medical College, Krakow, Poland
}

Adv Interv Cardiol 2018; 14, 1 (51): 95-98

DOI: https://doi.org/10.5114/aic.2018.74361

\section{Introduction}

Endothelium is the most inner layer of the artery which is crucially engaged in processes of vasodilatation. The regulation of blood flow is implemented due to synthesis and release of nitric oxide (NO) distributed by eNOS, which causes the ability of the artery to react to ischemia [1-3]. Nitric oxide primarily dilates the artery but is also a protective factor which lowers the inflammatory response in the artery [2-4]. It has been proven that dysfunction of the endothelium due to lowered bioavailability of NO is a key factor in the origin of atherosclerosis and may lead to higher risk of heart-vascular mortality [2-4].

The radial approach is the most preferred option during performing percutaneous coronary intervention $(\mathrm{PCl})$. Its superiority compared to the femoral access is reflected in a lowered rate of periprocedural death and lowered risk of mortality established [4-12] on reduction of major bleeding and access site complications, which is crucially important in therapy engaging greater anticoagulation [13-15]. Comfort of the patient and earlier mobilization are additional advantages $[5,7]$. It seems that over $90 \%$ of all coronary angiographies and PCls can be performed using a radial approach and in Poland the radial artery has become the default approach for angiography and $\mathrm{PCI}[16,17]$. However, inserting the catheter sheath by the radial approach during $\mathrm{PCl}$ and coronary angiography procedures traumatizes the inner layer of the artery and negatively affects the synthesis of NO [1]. Nevertheless, the distinct impact of invasive procedures on the vascular response of arteries is not well known yet. One way of examining the function of endothelium is by flow-mediated dilatation (FMD). It compares the radial artery diameter before and after ischemia caused by clenching the cuff on the arm $[3,4]$. Therefore, measure- ment of this parameter and blood flow velocity of the radial artery before and after invasive procedures may seem to be the best option to determine how endothelial function is impaired by catheter and sheath maneuvers.

\section{Aim}

The aim of this study is to compare endothelial function before and after invasive coronary procedures (angiography, $\mathrm{PCl}$ ).

\section{Material and methods}

Informed written consent was obtained from 15 male patients. They were recruited prospectively from the list of subjects requiring elective coronary catheterization for coronary angiography or angioplasty with stable angina admitted to our department. The exclusion criteria were: changing radial access site (right vs. left), changing access site to femoral, occlusion of both radial arteries, hemodialytic fistula, acute coronary syndrome. The study was evaluated positively by the local Ethics Committee and was also conducted in compliance with the Declaration of Helsinki and its later amendments. The radial approach was performed by the standard Seldinger method. The procedure was performed by experienced PCI operators who perform at least 50 procedures by radial access per month. In most cases a standard 6 Fr sheath and catheters were used at the discretion of the operator. All sheaths were removed at the end of the procedure and pressure dressing was applied.

Examination consisted of two parts - measuring radial artery blood flow $(\mathrm{cm} / \mathrm{s})$ and diameter $(\mathrm{mm})$ before and after clenching the arm. Patients were examined twice: before planned $\mathrm{PCl}$ or coronary angiography and then after the abovementioned procedure (up to $24 \mathrm{~h}$ ).

\section{Corresponding author:}

Karol Sabatowski, $2^{\text {nd }}$ Department of Cardiology and Cardiovascular Interventions, University Hospital, 17 Kopernika St, 31-501 Krakow, Poland, phone: +48 696530 018, e-mail: sabatowski.ka@gmail.com

Received: 8.08.2017, accepted: 7.12.2017. 
Examination took place in quiet, comfortable examination room, after $30 \mathrm{~min}$ of rest, and at least $30 \mathrm{~min}$ refraining from smoking. During the measurement patients were sitting in a relaxed pose with the arms loosely hanging down their side. Using an ultrasound transducer patients' radial arteries were examined to measure the blood flow velocity (BFV) and the diameter (A). After that the patient's arm was clenched with cuff for 5 min using pressure of $>200 \mathrm{~mm} \mathrm{Hg}$ and the same procedure was implemented after unclenching the arm - values were measured in the $15^{\text {th }} \mathrm{s}$ and $60^{\text {th }} \mathrm{s}$ after unclenching, sequentially BFV and the diameter (B) [18]. The ultrasound transducer was placed about $10 \mathrm{~cm}$ above the patient's wrist. Obtained diameters allowed calculation of the FMD parameter following the formula: $B-A / A$. The measurements were performed by an experienced physician using a Philips portable Doppler ultrasound machine with $12-\mathrm{MHz}$ multifrequency linear array probe attached to a high-resolution display in order to provide images and gain the exact blood flow and diameter values.

\section{Statistical analysis}

Standard descriptive statistics were used in the analysis. Quantitative variables were described using mean and standard deviation. Categorical variables were presented as counts and percentages. The level of statistical significance was set at $p<0.05$. The Mann-Whitney $U$ test (for non-normal distribution of data) or unpaired (two-sample) Student's t-test (for normally distributed data) was applied for continuous variables. The $\chi^{2}$ test

Table I. Baseline characteristics of patients

\begin{tabular}{lc} 
Parameter & Percentage \\
\hline Sheath size $-6 \mathrm{Fr}$ & 100 \\
\hline Arterial hypertension & 100 \\
\hline COPD & 14.3 \\
\hline Hypercholesterolemia & 87.5 \\
\hline Active smokers & 14.3 \\
\hline Ex-smokers & 57.1 \\
\hline Non-smokers & 28.6 \\
\hline PCl in past medical history & 71.4 \\
\hline Impaired fasting glycemia & 36 \\
\hline Dilated cardiomyopathy after myocardial infarction & 14.3
\end{tabular}

was used for categorical (nominal and dichotomous) variables. All analyses were carried out with Statistica 12 (StatSoft, Inc. Tulsa, OK, USA).

\section{Results}

The mean age of patients was $63.3 \pm 7.8$. Clinical characteristics of patients are presented in Table I. Tables II and III show changes in blood flow velocity during the FMD examination.

The possible factors affecting FMD and BFV such as smoking, history of $\mathrm{PCl}$ or additional impaired fasting glycemia (IFG) are analyzed in Table IV.

The results show that not only FMD but also BFV significantly decreases. We should also mention that postclenching BFV values are insignificant according to statistical measurement. Other comorbidities such as diabetes or hypercholesterolemia seem not to be related to FMD and BFV values. Also use of tobacco was suggested as a factor affecting FMD because active smokers and ex-smokers seem to be a group of higher risk of endothelial dysfunction; however, the results do not show a statistically significant association between FMD value and smoking. Ex-smokers formed the highest percentage of the study group, so in order to validate this correlation, wider patient recruitment with further analysis needs to be done. According to the tables also prior $\mathrm{PCl}$ seems not to be related to endothelial dysfunction. However, $70 \%$ of the study group had prior $\mathrm{PCl}$. Because of that, these results also need further analysis.

\section{Discussion}

The main results of the study show that artery diameter significantly drops, as does FMD value and preclenching BFV. Also postclenching BFV drops but it is not statistically significant. The abovementioned results clearly indicate endothelial dysfunction especially with lower synthesis of NO. However, the results clearly shows that crucial correlations with endothelial dysfunction and other comorbidities need further analysis. A prior $\mathrm{PCl}$ procedure seems to be one possible factor affecting the FMD and BFV values in patients undergoing catheterization using the radial approach. However, our study revealed that there is no such correlation between these values and previous intervention. The FMD and BFV values of patients undergoing the procedure for the first time were not significantly different compared to the group that had prior $\mathrm{PCl}$. Furthermore, we found no statistical significance in influence relating to

Table II. Results of radial artery diameter during FMD examination

\begin{tabular}{|c|c|c|c|}
\hline Variable & $\begin{array}{c}\text { Before clenching }[\mathrm{cm} / \mathrm{s}] \\
\text { Mean } \pm \text { SD }\end{array}$ & $\begin{array}{c}\text { After clenching }[\mathrm{cm} / \mathrm{s}] \\
\text { Mean } \pm \text { SD }\end{array}$ & $P$-value \\
\hline Before catheterization & $60.6 \pm 15.0$ & $72.0 \pm 16.1$ & 0.04 \\
\hline After catheterization & $46.9 \pm 14.3$ & $62.9 \pm 17.5$ & 0.005 \\
\hline
\end{tabular}


Table III. The FMD and BFV before and after procedure

\begin{tabular}{lccc} 
Parameter & $\begin{array}{c}\text { Before catheterization } \\
\text { Mean } \pm \text { SD }\end{array}$ & $\begin{array}{c}\text { After catheterization } \\
\text { Mean } \pm \text { SD }\end{array}$ & $P$-value \\
\hline FMD $(\%)$ & $19.8 \pm 10$ & $7.6 \pm 6$ & 0.006 \\
\hline Flow preclenching measurement $($ basal) $[\mathrm{cm} / \mathrm{s}]$ & $60.6 \pm 15$ & $46.87 \pm 14.32$ & 0.007 \\
\hline Flow postclenching measurement $[\mathrm{cm} / \mathrm{s}]$ & $72.0 \pm 16.1$ & $62.9 \pm 17.5$ & 0.29
\end{tabular}

Table IV. Analysis of comorbidities vs. FMD and BFV measurements ( $p$-values)

\begin{tabular}{lcccc} 
Parameter & Catheterization & $\begin{array}{c}\text { Never smoked vs. } \\
\text { smoked/smokes }\end{array}$ & $\begin{array}{c}\text { PCI in the past vs. } \\
\text { non PCI }\end{array}$ & $\begin{array}{c}\text { Impaired fasting glyce- } \\
\text { mia vs. normal glycemia }\end{array}$ \\
\hline & Pre & 0.25 & 1 & 0.49 \\
\cline { 2 - 5 } & Post & 0.39 & 1 & 0.08 \\
\hline Blood flow preclenching & Pre & 0.33 & 0.56 & 0.69 \\
\cline { 2 - 5 } & Post & 0.56 & 0.85 & 0.59 \\
\hline Blood flow postclenching & Pre & 0.11 & 0.82 & 0.71 \\
\cline { 2 - 5 } & Post & 0.82 & 0.49 & 0.14
\end{tabular}

vascular sheath diameter, with the same observation for the BFV parameter.

Despite of nuclear results of the correlation between FMD and comorbid conditions it should be mentioned that FMD significantly indicates the cardiac artery disease burden. According to Manganaro et al. [19] reduced FMD is the only significant independent predictor of the presence of $C A D$ and CAD severity. This fact leads to reflection that the radial artery FMD could also be a predictor which needs further analysis.

Measuring FMD could be a predictor for access to other radial interventions. According to Ruiz-Salmerón et al. [20] using wider catheters - 3 Fr or more - can cause radial artery spasm more frequently. This is why it is probable that measuring the FMD value can help in evaluating whether the radial access is possible. A more significant drop could be a predictor of more plausible need of using the femoral artery instead of the radial artery or choosing different size or sheathless catheters. However, we are aware that it may not have prognostic significance because of not assessing FMD in the brachial artery. Goldsmit et al. [21] stated that the catheter for spasm is usually $7 \mathrm{Fr}$ or more. According to that information FMD could be also measured for checking complications after using a wider sheath or catheter, which needs further analysis.

Previous PCls according to the results do not affect the FMD drop. Gathering further information might help explaining this aspect. Furthermore, it is likely that by measuring FMD which will be significantly decreased we can conclude that the next PCI will impair the function of the artery.

Due to elderly patients enrolled in this study it was not possible to investigate differences in dilatation of radial arteries in younger patients. However, the artery of one younger patient seemed to endure the procedure better than other patients (data not shown). Because of the abovementioned observation this parameter also needs further analysis.

We also found no difference for patients with impaired fasting glycemia (unfortunately, no diabetic patients were enrolled); however, this might be a consequence of the relatively small sample size. According to Wu et al. [22] high glucose levels seem to impair the endothelial function.

Patients were divided into those who had stopped smoking, still smoke or those who never smoked. Examination did not show a correlation between smoking and endothelial function. The FMD value changes also do not seem to be related to previous smoking. It is probable that enrolling more patients could solve the problem of statistical insignificance.

\section{Conclusions}

There is a significant difference between FMD and BFV values before and after $\mathrm{PCl}$. Comorbidities such as impaired fasting glycemia and hypercholesterolemia do not seem to affect the capacity of the artery for dilatation. FMD could be a prognostic factor for performing new interventions, but this conclusion also requires assessing FMD in the brachial artery. Further studies are needed to confirm these observations.

\section{Conflict of interest}

The authors declare no conflict of interest.

\section{References}

1. Radomski MW, Palmer RMJ, Moncada S. Comparative pharmacology of endothelium - derived relaxing factor, nitric oxide and prostacyclin in platelets. Br J Pharmacol 1987; 92: 181-7. 
2. Dawson E, Rathore S, Cable T, et al. Impact of introducer sheath coating on endothelial function in humans after transradial coronary procedures. Circ Cardiovasc Interv 2010; 3: 148-56.

3. Fathi R, Haluska B, Isabel N, et al. The relative importance of vascular structure and function in predicting cardiovascular events. J Am Coll Cardiol 2004; 43: 616-23.

4. Okuyan H, Açikgoz SK, Tacoy G, et al. Effect of transradial coronary angiography procedure on vascular diameter and vasodilator functions in the access site. Angiology 2013; 64: 515-21.

5. Pal R, Bagarhatta R, Rathore M. A descriptive comparison of diameter of radial and ulnar arteries using Doppler ultrasonography. Indian J Basic Appl Med Res 2014; 3: 373-9.

6. Siudak Z, Tokarek T, Dziewierz A, et al. Reduced periprocedural mortality and bleeding rates of radial approach in ST-segment elevation myocardial infarction. Propensity score analysis of data from the ORPKI Polish National Registry. Eurolntervention 2017; 13: 843-50.

7. Rutka JK, Bryniarski K, Tokarek T, et al. Comparison of patient comfort after coronary angiography by standard arterial access approaches. Kardiol Pol 2016; 74: 68-74.

8. Ando G, Capodanno D. Radial access reduces mortality in patients with acute coronary syndromes: results from an updated trial sequential analysis of randomized trials. JACC CardiovasC Interv 2016; 9: 660-70.

9. Jolly SS, Yusuf S, Cairns J, et al. Radial versus femoral access for coronary angiography and intervention in patients with acute coronary syndromes (RIVAL): a randomised, parallel group, multicentre trial. Lancet 2011; 377: 1409-20.

10. Rao SV, O'Grady K, Pieper KS, et al. Impact of bleeding severity on clinical outcomes among patients with acute coronary syndromes. Am J Cardiol 2005; 96: 1200-6.

11. Eikelboom JW, Mehta SR, Anand SS, et al. Adverse impact of bleeding on prognosis in patients with acute coronary syndromes. Circulation 2006; 114: 774-82.

12. Manoukian SV, Feit F, Mehran R, et al. Impact of major bleeding on 30-day mortality and clinical outcomes in patients with acute coronary syndromes: an analysis from the ACUITY trial. J Am Coll Cardiol 2007; 49: 1362-8.

13. Mann T, Cubeddu G, Bowen J, et al. Stenting in acute coronary syndromes: a comparison of radial versus femoral access sites. J Am Coll Cardiol 1998; 32: 572-6.

14. Mahmud E, Patel M. Radial access for ST-segment elevation myocardial infarction interventions: does it really lower mortality? J Am Coll Cardiol Intv 2013; 6: 824-6.

15. Doyle BJ, Rihal CS, Gastineau DA, et al. Bleeding, blood transfusion, and increased mortality after percutaneous coronary intervention: implications for contemporary practice. J Am Coll Cardiol 2009; 53: 2019-27.

16. Siudak Z, Zawislak B, Dziewierz A, et al. Transradial approach in patients with ST-elevation myocardial infarction treated with abciximab results in fewer bleeding complications: data from EUROTRANSFER registry. Coron Artery Dis 2010; 21: 292-7.

17. Legutko J, Siudak Z, Parma R, et al. Poland: coronary and structural heart interventions from 2010 to 2015. Eurointervention 2017; 13: Z51-4.

18. Corretti MC, Anderson TJ, Benjamin EJ, et al. Guidelines for the ultrasound assessment of endothelial-dependent flow-mediated vasodilation of the brachial artery: a report of the International Brachial Artery Reactivity Task Force. J Am Coll Cardiol 2002; 39: 257-65.
19. Manganaro A, Ciraci L, Andre L, et al. Endothelial dysfunction in patients with coronary artery disease: insights from a flow-mediated dilation study. Clin Appl Thromb Hemost 2014; 20: 583-8.

20. Ruiz-Salmerón RJ, Mora R, Vélez-Gimón $M$, et al. Radial artery spasm in transradial cardiac catheterization. Assessment of factors related to its occurrence, and of its consequences during follow-up. Rev Esp Cardiol 2005; 58: 504-11.

21. Goldsmit A, Kiemeneij F, Gilchrist IC, et al. Radial artery spasm associated with transradial cardiovascular procedures: results from the RAS registry. Catheter Cardiovasc Interv 2014; 83: E32-6.

22. Wu Y, Lee S, Bobadilla $S$, et al. High glucose-induced p53 phosphorylation contributes to impairment of endothelial antioxidant system. Biochim Biophys Acta 2017; 1863: 2355-62. 